\title{
The Florence Picpoems
}

\author{
picpoet
}

Picpoetry is the process of combining iphoneography and instant text writing. It is a practice initiated by picpoet, an iphoneographer, writer and performer. Picpoems are immediately uploaded on picpoet's account on Instagram and also fed into picpoet's website picpoet.net. The text draws from the visual of the photograph but also attempts to capture the multisensorial atmosphere of the particular time and space in which the photos are taken. The text must be written quickly while immersed in the specific space, and remain unedited, in an imitation of automatic writing, but with the atmospheric imprint on it.

The Florence Picpoems is a series commissioned by Ric Mohr and Nadir Hosen, the organisers of the International Symposium on Technologies of Law and Religion: Representation, Objects and Agency that took place in the Prato Centre of Monash University in Prato, Tuscany, on 
the 13-15 June 2016. Part of the symposium was a guided visit to the Monastero di San Marco in Florence. Picpoet was asked to create a series of picpoems drawing from the visit to the city of Florence in general, and the visit to the monastery in particular.

The picpoems reflect on such issues as law and justice, legal spatiality and temporality, agency, digitalisation and AI in relation to the law, objects and materiality, bodies and movement, and so on. The connection between the textual and the visual is tight and parallel, yet not descriptive. This allows questions on the relevance of the law in terms of affective, embodied and spatialised movements to emerge both pictorially and textually, and ultimately left unanswered. 


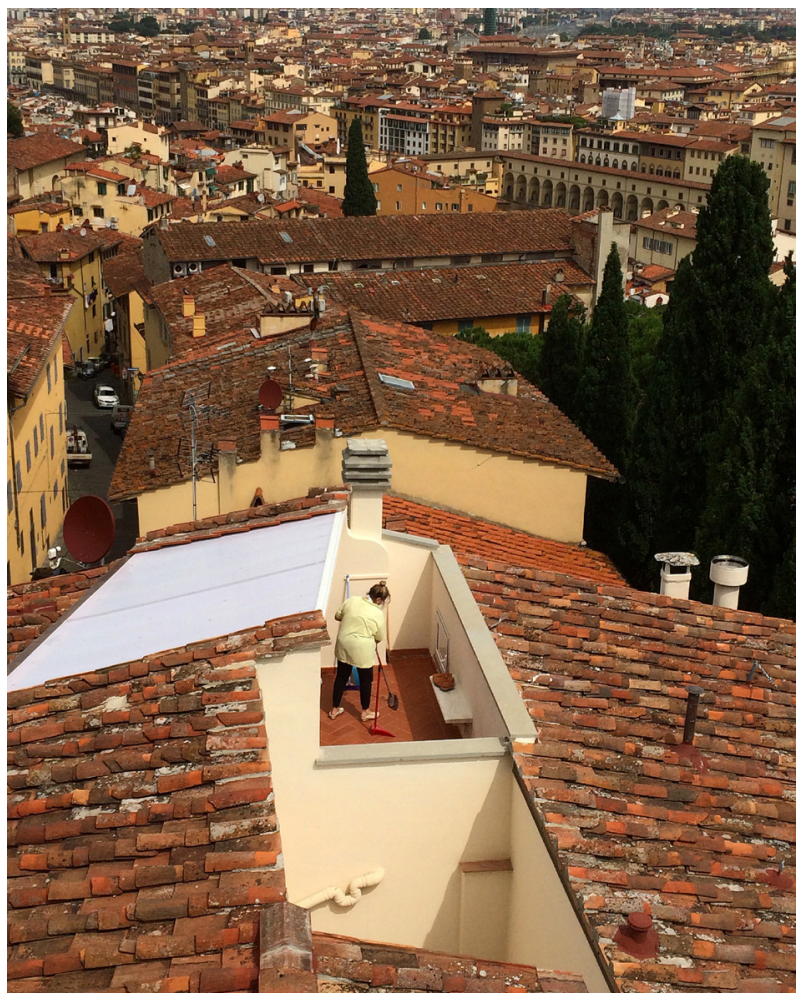

every morning she would sweep. she'd start from inside the villa, then the little balcony, and then little by little, she would sweep the roofs around her, and the antennas, and the palazzi, and the birds and clouds, even the big court hall at the end of the horizon, till all the city would be swept away, and before her a vast white sheet would flap in the wind. now I can set my own way, she thought. now I can move in any way I want.

we are striations, craving for smoothness. 


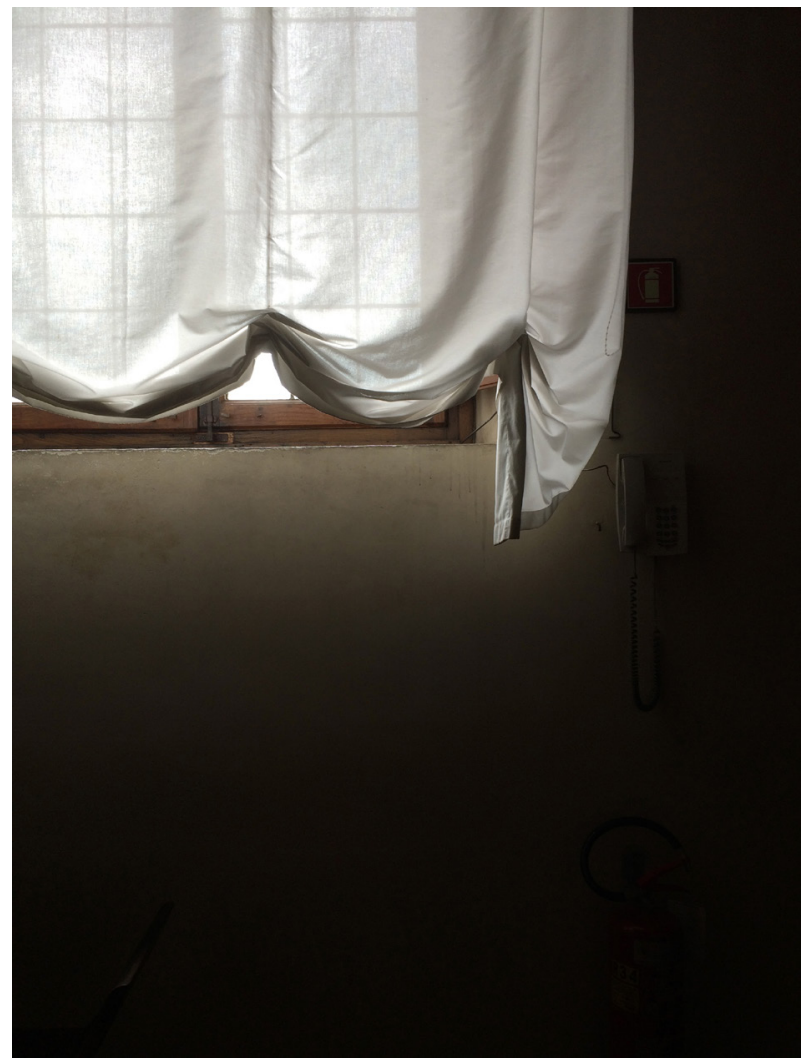

chop me up. there are others coming this way. same others. same skin same breath same world, assemblages of oneness, jelly singularities of wholeness. a whiff of a summer breeze lifting that drape you placed in front of our being - this is all it takes for the wave of the other law to blind us.

we are awake, slumberous eyes of an anthropocenic chain. 


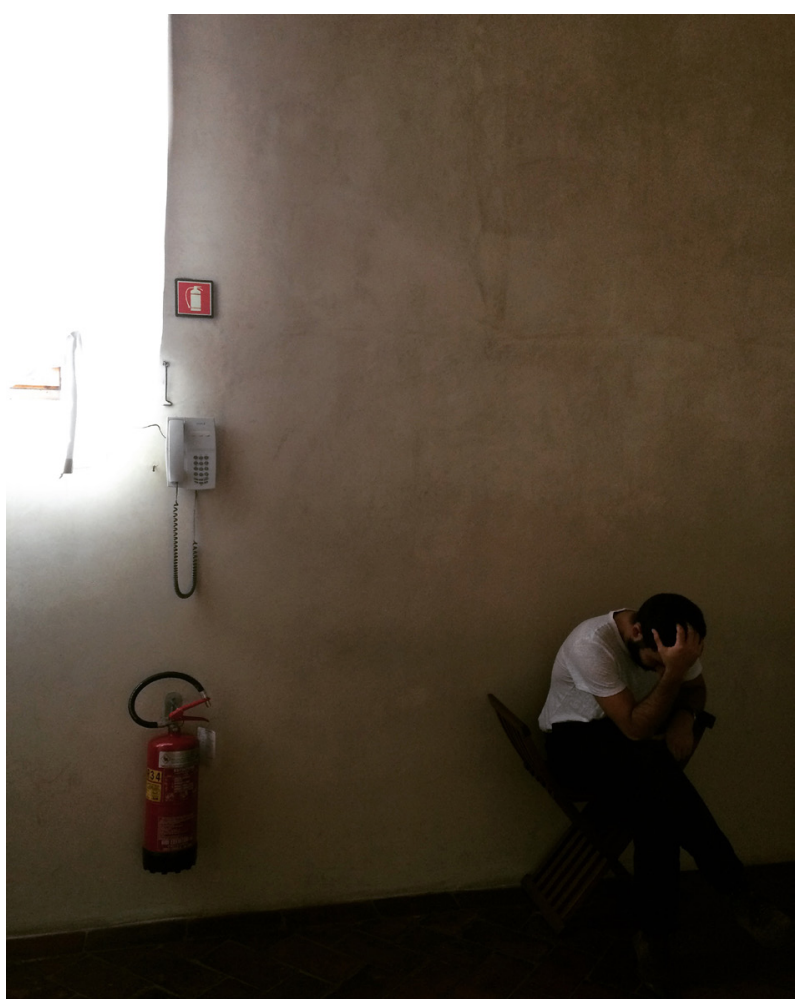

a force of invitation. you are now in, parasite and host at the same time, pulling my entrails and commanding my desires. this is not an ethical hotel where we serve faces on platters and otherness as first dish. this is the beast of all our fears, settling a conflict without judge, following the violence between our bodies. theatre and presence, residual technologies of self.

we have grown up, beyond little numerical moralities, and we are afraid. 


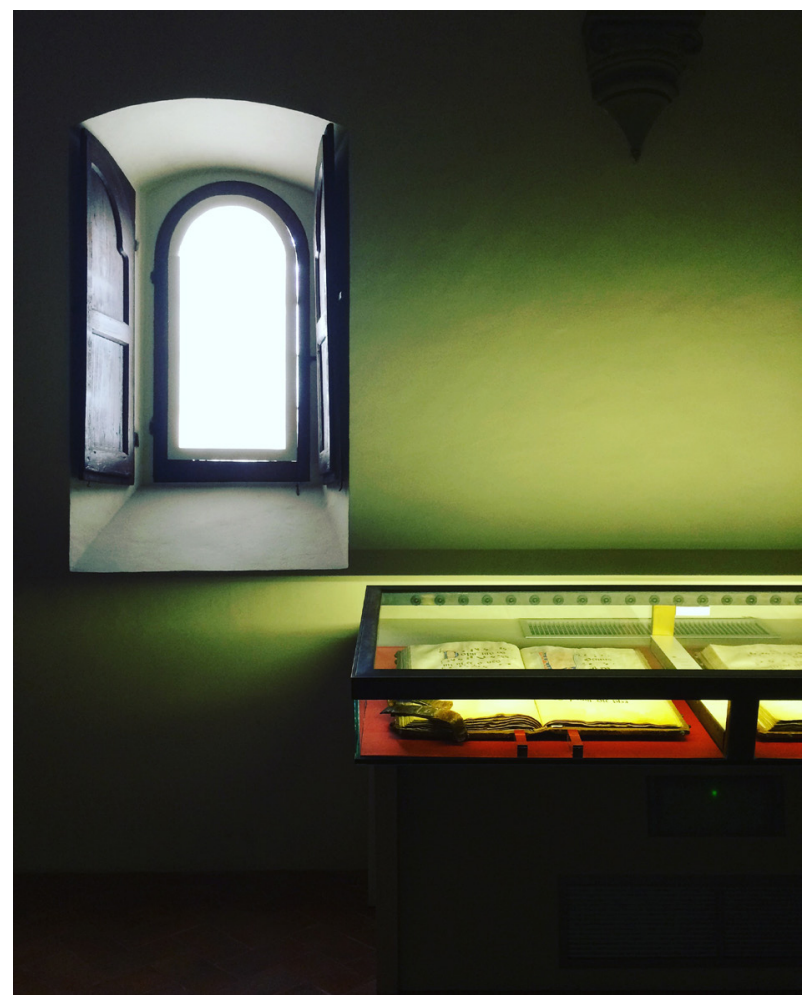

liquid never, airy nowhere, our digitalisation feels complete. we are such stuff as nothing is made of, riding space like demons at night, defying time like gods' repose. we carry a secret in our pocket, the way of our whole where nothing is not part of it and where all parts dissect into fractal furthermores, brittle lawscapes of pixelled collapse. something is laughing somewhere at us. it might be the battery, it might be the real future.

we are never whole, we are never part. 


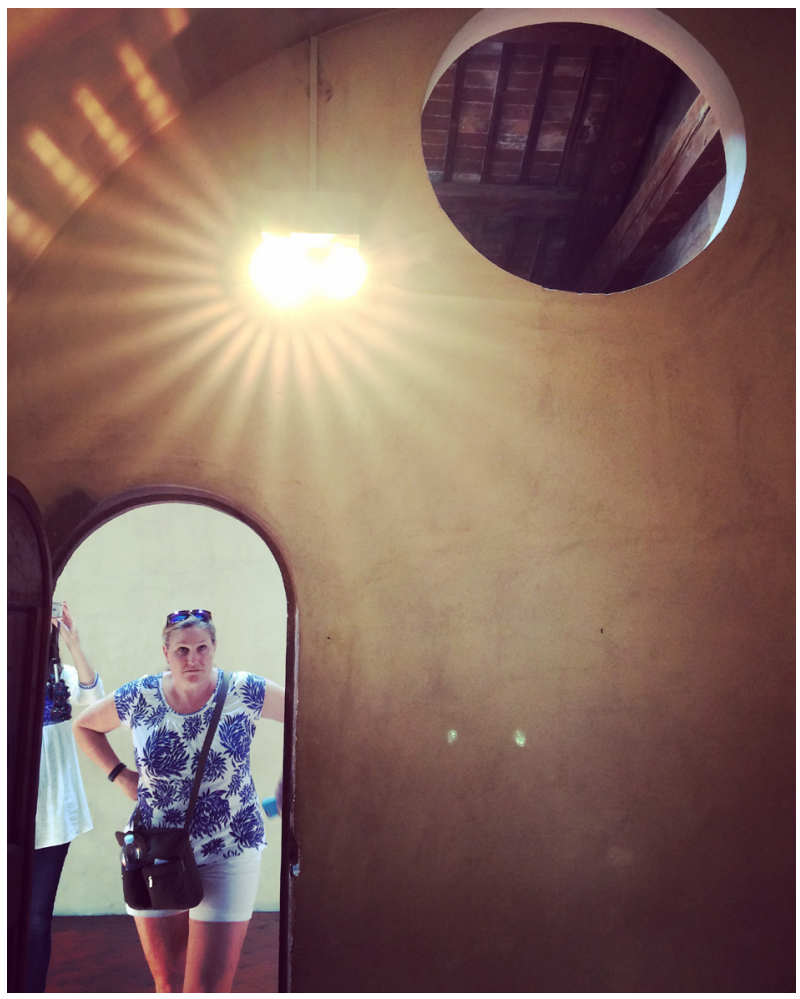

come in. this gate is for you. I've opened it with my statutes, I've carved it around your shape, all paragraphs sectioning your limbs. can't you see? it's the perfect fit. it is what you've always desired. it is your wetness, your darkness, your aftertaste. it is so soft that it'll feel like a part of your own body, an extension of your saliva, a pool of arms holding you up in dream of other worlds. come in. we are waiting. we are the guardians of the gate.

no? it's ok. this gate will never leave you. 


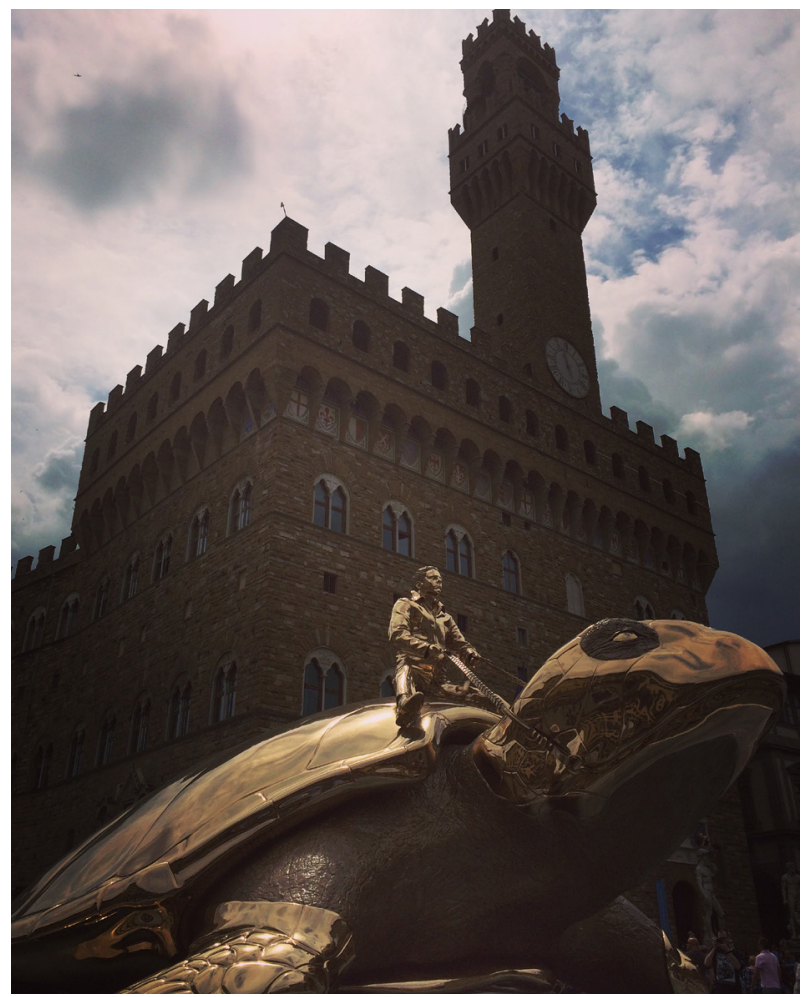

every afternoon, my inhumanity tickles my thighs, rising force of a geology without logos. in the evening, all is smoothness: I lay where I'm laid, drenched in the whispers of my biology. I am tired of this body, you see? all human, no space for the screams that gallop through my mind and my veins when all is silent. and so we try to silence it.

we are inhuman stories of a mineral flesh. 


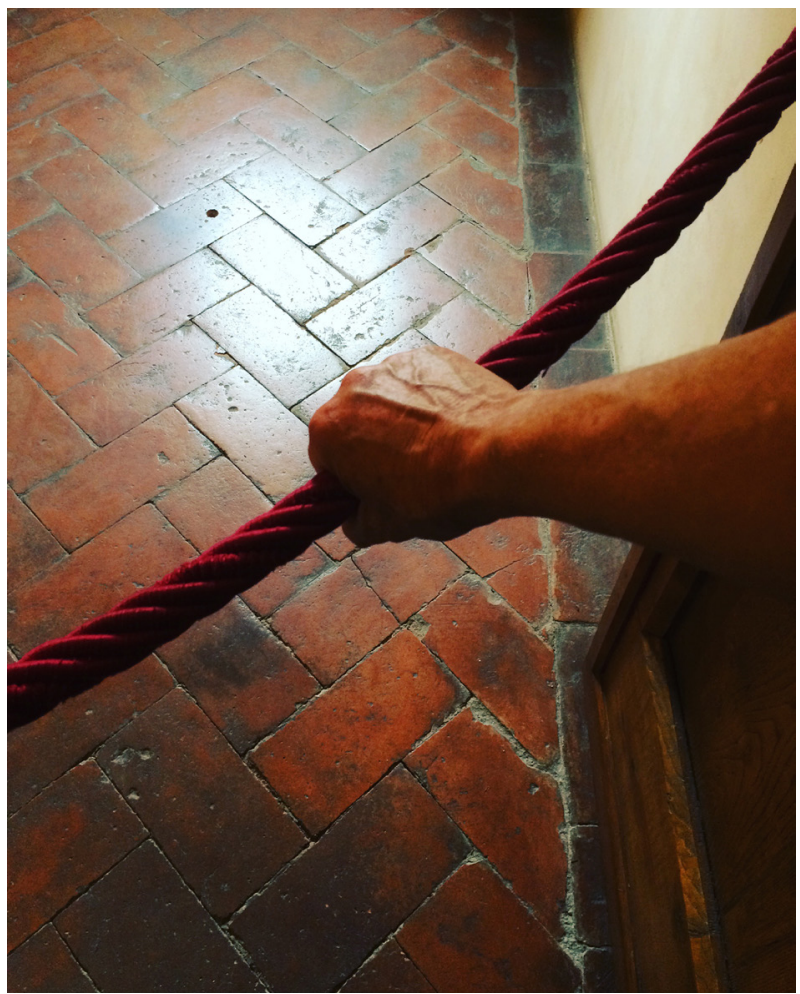

hold my object like a planet rests on a god's lap: gently and with future streaming through your fingers. this is my armour, the boundary of my life, poor technology against death. preserved, my object lasts aeons of falls. even when your hand, sometimes revolutionary, often in ignorance, lets it fall, it bounces back following its own just emplacement.

we are hands holding while breaking, lest we fall. 


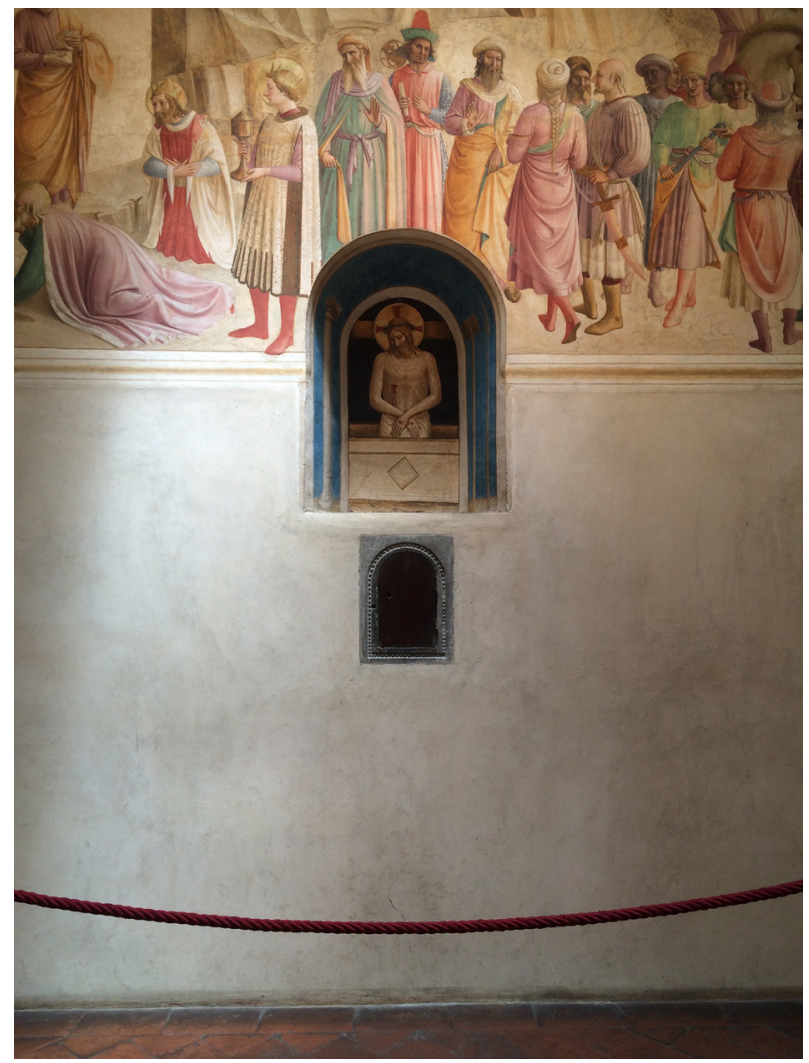

she kept on digging, nails and teeth screeching on the surface of the earth. she had this idea, sliding on the light that she thought was coming heavenway: she had to see behind. the world a fruit lost in the palimpsest of the city, rotting but pure still. so she thought and so she dug. the world got thin like a petal and her nails and teeth dust - and the behind is still behind.

we are surfaces turned inside. 


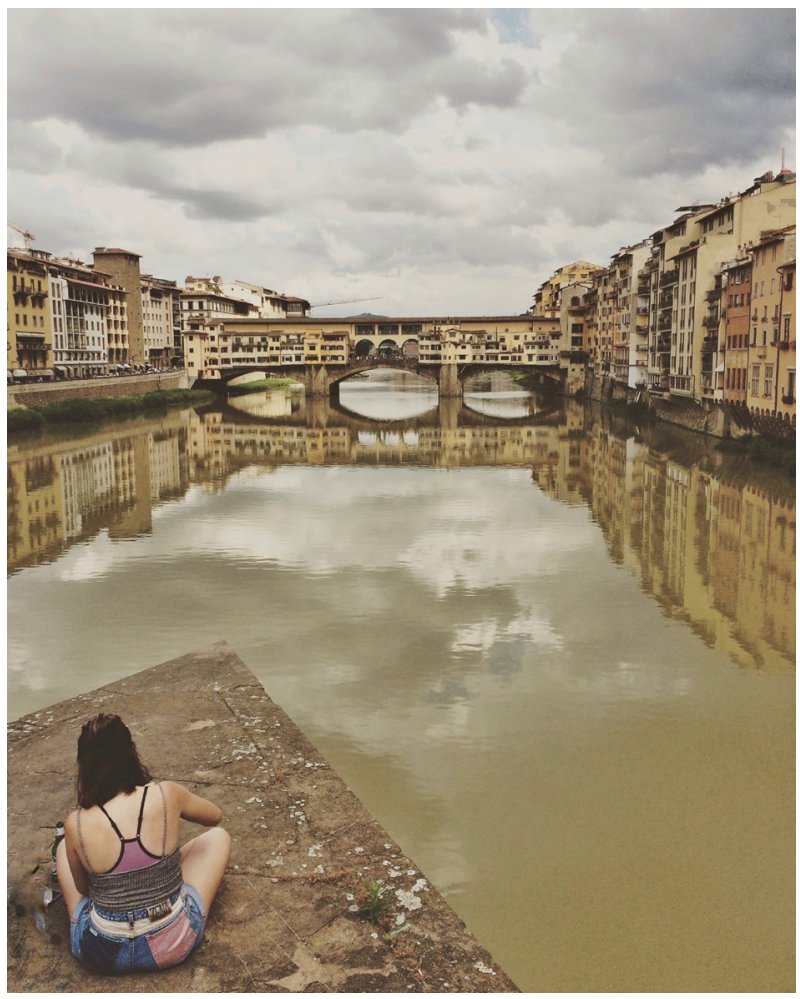

we would ride that cement carpet flying high into the city of order. we would speak with the soaring birds. we would dive with them, clouds heavy with the tears of gods, air bloated with the fumes of the padding boats.

our happiness was easy, precious and polluted. 
